\title{
Efectos No Genéticos sobre la Reproducción en Vacas Mestizas con Predominio Bos indicus en el Municipio de Arauca, Colombia
}

\author{
Non-Genetic Effects on Reproduction in Crossbreed Cows with Bos indicus \\ Predominance in the Municipality of Arauca, Colombia
}

Arcesio Salamanca C. ${ }^{1,3}$, Mauricio Vélez T. ${ }^{2}$, Jannet Bentez M. ${ }^{1}$

\section{Resumen}

\begin{abstract}
El objetivo del estudio fue determinar algunos factores no genéticos que afectan la edad al primer parto (EPP) y el intervalo entre partos (IEP) en vacas doble propósito en el municipio de Arauca, Colombia. Se analizó la información de 110 y 168 registros de EPP e IEP de vacas con predominio de Bos indicus. Se consideró el efecto de los factores fijos para EPP: Finca (FIN: 1,2,3), época de primer parto (EPPP: seca, lluviosa), año de primer parto (APP: 1992 ...2011), sexo de la cría (SCR: M, H); y para IEP: FIN, época de intervalo entre partos (EIP), año de intervalo entre partos (AIEP), SCR y número de parto (NP: 1...5). Los datos se analizaron utilizando los procedimientos GLM de SAS y para la comparación de medias se usó el test de Duncan, con un nivel de significancia de 5\%. La media estimada para la EPP fue de $1243.6 \pm 160.3$ días y para IEP de $608.0 \pm 165.4$ días. FIN y APP fueron factores de variación significativos $(\mathrm{p}<0.05)$ para EPP, mientras que NP y AIEP fueron factores de variación significativos $(p<0.05)$ para IEP. Se concluye que la influencia de la finca, el año de parto, el año de intervalo entre partos y el número de parto sobre los parámetros reproductivos en vacas mestizas de doble propósito criadas en el trópico de Cauca, Colombia, están relacionados con el manejo técnico y productivo propio de cada finca; asimismo, la edad al primer parto y el intervalo entre partos en las fincas en estudio se encuentran dentro de los rangos considerados como aceptables para el sistema de producción en sabana inundable.
\end{abstract}

Palabras clave: cruzamiento, parto, edad, clima tropical

\footnotetext{
${ }^{1}$ Grupo de Investigaciones Los Araucos, Facultad de Medicina Veterinaria y Zootecnia, Universidad Cooperativa de Colombia, Arauca, Colombia

${ }^{2}$ Facultad de Ciencias Agropecuarias, Universidad Nacional de Colombia, Palmira, Colombia

${ }^{3}$ E-mail:asaca_65@yahoo.es
}

Recibido: 4 de mayo de 2016

Aceptado para publicación: 8 de octubre de 2016 
The aim of this study was to determine some non-genetic factors that affect age at first calving (AFC) and the interval between calving (CI) in dual purpose cows in the municipality of Arauca, Colombia. Records related to AFC $(n=110)$ and $\mathrm{CI}(\mathrm{n}=168)$ of cows with Bos indicus predominance were analyzed. The effect of fixed factors that were considered for EPP were: Farm (FAR: 1,2,3), season of first calving (FCS: dry, rainy), year of first calving (FCY: 1992 ...2011), sex of calf(CS: M,F) and for CI: FAR, season of calving interval (SCI), year of calving interval (CIY), CS and parity number (PN: 1...5). Data was analyzed using the SAS GLM procedures and for the averages comparison was used the Duncan test with a significance level of 5\%. The estimated average for AFC was 1243.6 \pm 160.3 days and for CI was $608.0 \pm 165.4$ days. FAR and FCY were significant factors of variation $(p<0.05)$ for $C Y$, while NP and CIY were significant factors of variation $(p<0.05)$ for CI. It is concluded that the influence of farm, year of birth, year of calving interval and parity on reproductive parameters in crossbred cows reared under the tropical conditions of Cauca, Colombia is related to technical and productive management characteristics of each farm. Besides, age at first calving and calving interval on farms under study are within the ranges considered acceptable for the production system in flooded savanna.

Key words: breeding, calving, age, tropical climate

\section{INTRODUCCIÓN}

La toma de información en las fincas ganaderas no es usualmente llevada a cabo, y cuando se realiza, los datos son pocas veces procesados. El análisis de la información a nivel de finca permite identificar los factores que limitan o favorecen la producción y que condicionan la expresión de los parámetros reproductivos (García et al., 2002). La edad al primer parto y el intervalo entre partos son los parámetros de mayor importancia económica en el manejo reproductivo, inicio de la lactancia y vida útil de las vacas (González et al., 2007; Ossa et al., 2007; Vergara et al., 2009), y están afectados por la interacción de factores como la nutrición, el grupo racial, el peso al servicio, el año y la época de parto y número de parto (Arellano et al., 2006; Vergara et al., 2007).

La eficiencia reproductiva de las vacas se ve afectada por el retardo en la edad al primer parto, representando grandes pérdidas económicas al productor (Hernández et al., 2010); por tanto, entre más temprano inicie la novilla la vida productiva, mayor será el número de terneros y la leche producida durante su vida útil, contribuyendo a incrementar la productividad del hato y la longevidad de los animales (González et al., 2006; Vergara et al., 2009). Igualmente, en el trópico, las hembras bovinas se caracterizan por presentar anestros posparto mayores de 150 días, aumentando así los días de intervalo entre partos (Domínguez et al., 2004).

Los factores ambientales, tales como finca, año de parto, mes o época de parto y número de parto, afectan el comportamiento reproductivo de las vacas mestizas de doble propósito en condiciones del trópico americano; asimismo, pueden existir diferencias entre grupos raciales dentro de una misma finca (Corrión et al., 2002; López y Vaccaro, 2002; Medina y Pestana, 2005; Pino et al., 2009). Esto ha sido demostrado en México (Tuexi y Martínez, 2001; Arellano et al., 2006; Osorio y Segura, 2010), Colombia (Suárez et al., 2006; Vergara et al., 2009) y Brasil (Perotto et al., 2006a). 
En el municipio de Arauca, Colombia, se explota la producción ganadera del sistema de doble propósito mediante la introducción de razas lecheras Bos taurus, como la Holstein, Pardo Suizo y Ayrshire, las cuales se han cruzado con la población Bos indicus (cebú) existente, produciendo genotipos con alta proporción de genes cebú (Salamanca, 2008). No obstante, se requiere determinar las posibles influencias ambientales que afectan la reproducción de estos cruces como herramienta precisa para desarrollar un programa de mejoramiento genético.

La presente investigación tuvo como objetivo determinar los posibles factores ambientales que afectan la edad al primer parto y el intervalo entre partos en vacas mestizas con predominio Bos indicus del sistema doble propósito en el municipio de Arauca, Colombia.

\section{Materiales y Métodos}

\section{Lugar de Estudio}

El estudio se realizó en las fincas Tréquina, Las Vacas y Ranchería, las cuales se localizan en la región de sabana inundable con vegetación arbórea. La región, según la clasificación de Holdridge (1987), corresponde a la zona de vida Bosque Subhúmedo Tropical. El régimen de lluvias es básicamente monomodal, con una época seca o verano, que corresponde a los meses de noviembre a abril, y una época lluviosa o invierno, que corresponde a los meses de mayo a octubre. En general, la precipitación anual es menos de $1500 \mathrm{~mm}$.

El municipio se encuentra a una altitud de $128 \mathrm{~m}$, con temperatura ambiental de $35^{\circ} \mathrm{C}$ en marzo hasta $19{ }^{\circ} \mathrm{C}$ en enero, con humedad relativa que va desde el $65 \%$ en marzo hasta el $85 \%$ en los meses de junio y julio (Arauca, 2016; IDEAM, 2000).

\section{Población de Estudio}

La población bovina de las tres fincas está constituida por animales con proporciones Bos indicus-Bos taurus indefinidas, puesto que no se cuenta con registros genealógicos confiables.

El componente cebú en la finca Las Vacas es de Brahman, Sahiwal y Gucerá y el de Bos taurus es de Pardo Suizo, Simmental, Normando y Holstein; en la finca Tréquina es común la raza Brahman con Jersey, Romosinuano y Pardo Suizo; en tanto que en la finca Ranchería es el Brahman y Gyr en cruces con Pardo Suizo. La información genealógica fue suministrada por los respectivos ganaderos al momento de realizar el registro de los datos reproductivos.

En Las Vacas, las terneras destetadas son llevadas a potreros logrando un apropiado levante de la novilla; en las otras dos fincas, las terneras permanecen con la vaca en las mañanas y el destete se realiza según la decreciente producción de leche de la vaca.

Para el análisis de la información se trabajó solo con animales que tenían predominio Bos indicus, teniendo en cuenta su apariencia externa según lo recomendado por algunos autores (López y Vaccaro, 2002; Sheen y Riesco, 2002). Además, los animales seleccionados debían contar con información reproductiva completa para la edad al primer parto (Tréquina $=68$; Ranchería $=27$; Las Vacas $=15$ ) e intervalo entre partos (Ranchería $=72$; Tréquina $=71$; Las Vacas $=33$ ).

\section{Datos Analizados}

Se analizó la información de 110 y 168 datos de edad al primer parto (EPP) e intervalos entre partos (IEP), respectivamente, correspondientes al periodo 1992-2011.

En el modelo de análisis para EPP se consideraron los efectos: finca (FIN), época de primer parto (EPPP), año de primer parto 
(APP) y sexo de la cría (SCR). Debido a que el número de vacas en algunos años era pequeño, se analizó el factor año como regresión lineal sobre la EPP. En el modelo de análisis para IEP se consideraron los efectos: FIN, época de intervalo entre partos (EIP), año de intervalo entre partos (AIEP), donde el parto inicial fue el año base, SCR y número de parto (NP).

En la variable número de parto se consideraron vacas con 1 parto $(\mathrm{n}=75), 2$ partos $(n=52), 3$ partos $(n=27)$ y 4 partos $(n=14)$. Como época de parto (EP se consideraron la época seca (noviembre-abril) y la época lluviosa (mayo-octubre).

En el análisis estadístico se empleó el análisis de varianza y para determinar diferencias entre grupos se hizo la prueba de comparación de medias de Duncan con un nivel de significancia del 5\% (Kaps y Lamberson, 2004). Los datos se analizaron utilizando los procedimientos GLM de SAS (SAS, 2006). Se utilizó un modelo lineal para cada variable a evaluar.

El modelo estadístico para la variable edad al primer parto fue:

$Y_{i j k l}=\mu+\mathrm{a}_{\mathrm{i}}+\mathrm{b}_{\mathrm{j}}+\mathrm{c}_{\mathrm{k}}+\mathrm{d}_{1}+\mathrm{e}_{\mathrm{ijkl}}$

donde:

$Y_{i j k l}=$ variable dependiente estudiada (edad al primer parto)

$\mu=$ promedio poblacional

$a_{i}=$ efecto fijo de la finca $(i=1,2,3)$

$b_{j}=$ efecto fijo del sexo de la cría $(j=M, H)$;

$\mathrm{c}_{\mathrm{k}}=$ efecto fijo del año de primer parto $(\mathrm{k}=1992 \ldots .2011)$

$\mathrm{d}_{1}=$ efecto fijo de la época de primer parto (l=seca, lluviosa)

$\mathrm{e}_{\mathrm{ijkl}}=$ error experimental

El modelo estadístico para el variable intervalo entre partos fue:

$Y_{i j k l}=\mu+\mathrm{a}_{\mathrm{i}}+\mathrm{b}_{\mathrm{j}}+\mathrm{c}_{\mathrm{k}}+\mathrm{d}_{1}+\mathrm{f}_{\mathrm{m}}+\mathrm{e}_{\mathrm{ijklm}}$ dónde:

$Y_{i j k m}=$ variable dependiente estudiada (intervalo entre partos)

$\mu=$ promedio poblacional

$a_{i}=$ efecto fijo de la finca $(i=1,2,3)$ $\mathrm{b}_{\mathrm{j}}=$ efecto fijo del sexo de la cría $(\mathrm{j}=\mathrm{M}, \mathrm{H})$

$\mathrm{c}_{\mathrm{k}}=$ Efecto fijo del número de partos $(\mathrm{k}=1 \ldots 4)$

$\mathrm{d}_{1}=$ efecto fijo del año de intervalo entre partos $(1=1993 \ldots$ 2011)

$\mathrm{f}_{\mathrm{m}}=$ efecto fijo de la época de intervalo entre partos ( $\mathrm{m}=$ seca, lluviosa)

$\mathrm{e}_{\mathrm{ijk} k \mathrm{~m}}=$ error experimental

\section{Resultados y Discusión}

\section{Edad al Primer Parto}

La media general estimada y desviación estándar para la edad al primer parto se observa en el Cuadro 1. El promedio fue superior al reportado en la literatura en regiones tropicales en sistemas de producción de doble propósito (Arellano et al., 2006; Sánchez y Martínez, 2010; Motta et al., 2012; Chirinos y Faría, 2014). Sin embargo, fue ligeramente inferior a los 1314 días reportado para vacas mestizas del bajo Cauca y Antioquia (García et al., 2002) y los 1472 días para vacas Brahman y sus cruces en México (Osorio y Segura, 2010).

La finca Tréquima registró la menor edad al primer parto $(p<0.05)$. Estas diferencias pueden ser debido a las condiciones de manejo particulares de cada finca (Sánchez y Martínez, 2010). Algunos animales de Las Vacas fueron adquiridos en otras regiones, las fechas de parto no eran confiables y fue la finca con mayor diversidad de razas cebuínas. Asimismo, en algunas fincas se realiza la suplementación con fuente energética como pastos de corte y, en algunos casos, en la finca Tréquina con forrajes no convencionales como ensilaje de melina. Por otra parte, el Bos indicus se destaca por una pubertad tardía (De Alba, 1985), lo que podría estar afectando la edad al primer parto en el presente estudio.

El año del primer parto presentó variación significativa $(\mathrm{p}<0.05)$, coincidiendo con resultados en regiones tropicales (Arellano et al., 2006; Perotto et al., 2006a; Osorio y 
Cuadro 1. Promedio de edad al primer parto (en días) de vacas mestizas doble propósito con predominio Bos indicus en tres fincas del municipio de Arauca, Colombia

\begin{tabular}{|c|c|c|c|}
\hline Variable & & $\begin{array}{l}\text { Vacas } \\
\text { (n) }\end{array}$ & Promedio \\
\hline \multirow[t]{3}{*}{ Finca } & Las Vacas & 15 & $1,344.3 \pm 48.0^{\mathrm{a}}$ \\
\hline & Ranchería & 27 & $1,141.6 \pm 49.6^{\mathrm{b}}$ \\
\hline & Tréquina & 68 & $1,057.4 \pm 44.3^{b}$ \\
\hline Promedio general & & 110 & $1,243.6 \pm 160.3$ \\
\hline
\end{tabular}

Segura, 2010; Sánchez y Martínez, 2010); sin embargo, Chirinos y Faría (2014) no encontraron diferencias en cruces de bovinos mestizos con razas criollas Limonero y Carora.

La ecuación de la regresión lineal entre el año y la EPP fue: EPP $=-57326.1+29.2$ (año). La pendiente fue diferente de cero $(\mathrm{p}<0.05)$ y el ajuste de los datos fue alto $\left(\mathrm{R}^{2}=0.70\right)$, permitiendo indicar que la EPP mostró una tendencia a incrementarse en 29.2 días de un año a otro.

Las diferencias con respecto al año se consideran que son debidas a los cambios climáticos que afectan la disponibilidad de alimento, así como por los cambios en el manejo zootécnico y administrativo de cada finca. Por otro lado, entre 2004 y 2009 hubo un comportamiento uniforme en la edad al primer parto pero aumentó en 2010. Este cambio en 2010 pudo ser debido a que empezaron a reproducirse las novillas producto de inseminación artificial con semen de toros europeos como Jersey y Ayrshire, siendo estas afectadas por las condiciones ambientales debido al incremento de genes Bos taurus, especialmente en Las Vacas y Tréquina.

No se observaron diferencias estadísticas con respecto a la época del primer parto, pero las paridas en la época lluviosa presentaron promedios más bajos en relación con las paridas en época seca, coincidiendo con estudios en vacas Brahman y sus cruces en el trópico húmedo de México (Osorio y Segura, 2010). La no influencia de la época de parto permite que los productores puedan mantener una parición a lo largo del año y obtener ingresos constantes por la producción diaria de leche.

Las vacas que parieron crías hembras presentaron 49.9 días adicionales para el primer parto que aquellas que parieron machos; sin embargo estas diferencias no fueron significativas, coincidiendo con lo reportado para vacas Chianina, Canchim y Romosinuano (Azevêdo et al., 2006; Perotto et al., 2006a; Suarez y Pérez, 2006).

\section{Intervalo entre Partos}

La media general estimada y la desviación estándar para el intervalo entre partos se observa en el Cuadro 2. El promedio fue superior al reportado en la literatura en regiones tropicales en sistemas de producción doble propósito (Perotto et al., 2006b; Simón et al., 2010; López-Montilla, 2012; Coronado et al., 2015).

El intervalo entre partos podría estar afectado por la confiabilidad de los datos, dado que en algunas fincas existe un constante cambio de administradores, lo cual puede determinar que no haya un seguimiento permanente para el registro adecuado de la in- 
Cuadro 2. Promedio de intervalo entre partos (en días), según número de parto y año de intervalo entre partos de vacas mestizas doble propósito con predominio Bos indicus en tres fincas del municipio de Arauca, Colombia

\begin{tabular}{lccc}
\hline Variable & & $\begin{array}{c}\text { Vacas } \\
(\mathrm{n})\end{array}$ & Promedio \\
\hline Número de parto & 1 & 75 & $665.5 \pm 58.9^{\mathrm{a}}$ \\
& 2 & 52 & $596.5 \pm 60.7^{\mathrm{b}}$ \\
Año intervalo entre partos & 3 & 27 & $559.9 \pm 66.4^{\mathrm{b}}$ \\
& 4 & 14 & $449.4 \pm 71.0^{\mathrm{b}}$ \\
& 1993 & 2 & $355.5 \pm 137.6^{\mathrm{c}}$ \\
& 1994 & 3 & $404.9 \pm 180.3^{\mathrm{abc}}$ \\
& 1995 & 2 & $552.5 \pm 133.7^{\mathrm{abc}}$ \\
& 1996 & 1 & $453.6 \pm 183.7^{\mathrm{abc}}$ \\
& 1997 & 2 & $554.0 \pm 133.6^{\mathrm{abc}}$ \\
& 1998 & 3 & $484.7 \pm 133.9^{\mathrm{abc}}$ \\
& 2000 & 1 & $396.5 \pm 178.9^{\mathrm{abc}}$ \\
& 2002 & 2 & $614.0 \pm 184.0^{\mathrm{ab}}$ \\
& 2003 & 5 & $658.4 \pm 111.9^{\mathrm{ab}}$ \\
& 2004 & 1 & $294.9 \pm 182.8^{\mathrm{bc}}$ \\
& 2005 & 4 & $665.7 \pm 99.7^{\mathrm{ab}}$ \\
& 2006 & 8 & $593.1 \pm 76.4^{\mathrm{ab}}$ \\
2007 & 14 & $570.7 \pm 67.0^{\mathrm{ab}}$ \\
& 2008 & 21 & $546.9 \pm 58.2^{\mathrm{abc}}$ \\
& 2009 & 26 & $723.3 \pm 57.6^{\mathrm{a}}$ \\
& 2010 & $660.3 \pm 54.2^{\mathrm{ab}}$ \\
& & $648.7 \pm 56.0^{\mathrm{ab}}$ \\
& & $465.2 \pm 62.8^{\mathrm{abc}}$ \\
\hline
\end{tabular}

formación. Por otra parte, la literatura indica que el intervalo entre partos se extiende a medida que se incrementa la proporción de genes Bos taurus; así mismo, se considera que el mejor comportamiento reproductivo para los sistemas ganaderos de doble propósito en el trópico corresponde al F1 Bos taurus $x$ Bos indicus (López et al., 2010), situación que no coincide con el presente estudio don- de las vacas tienen mayor proporción de Bos indicus.

El mayor intervalo entre partos se presentó en vacas de primer parto $(\mathrm{p}<0.05)$, resultado que es ampliamente aceptado, considerando que las vacas jóvenes aún se encuentran en crecimiento (López y Vaccaro, 2002; Tadesse y Dessie, 2003; Osorio y Se- 
gura, 2010; López-Montilla, 2012). También es de esperarse que vacas con más de cinco partos puedan presentar intervalos entre partos más prolongados (Magaña et al., 2002; López et al., 2010).

El año influyó significativamente sobre el intervalo entre partos, coincidiendo con los resultados de otras investigaciones (Hernández et al., 2000; Arellano et al., 2006; Zambrano et al., 2006; Rodríguez y Martínez, 2010); sin embargo, en otros estudios el año no influyó sobre esta variable (Pino et al., 2009; Vergara et al., 2009; Osorio y Segura, 2010).

La finca, la época de parto y el sexo de la cría fueron factores independientes y no relacionados al intervalo entre partos. No obstante, las vacas que parieron en época lluviosa presentaron menores intervalos entre partos con respecto a las que parieron en la época seca, coincidiendo con otros reportes (Hernández et al., 2000; Arellano et al., 2006). Por otro lado, la época de parto, ante determinadas situaciones ambientales es un factor determinante para el intervalo entre partos en vacas mestizas (Vergara et al., 2009; López et al., 2010; Osorio y Segura, 2010; Rodríguez y Martínez, 2010).

\section{Conclusiones}

- La influencia de la finca, año de parto, año de intervalo entre partos y número de parto sobre los parámetros reproductivos en vacas mestizas de doble propósito criadas en el trópico está relacionada con el manejo técnico y productivo propio de cada finca.

- Los valores promedio de la edad al primer parto y del intervalo entre partos para vacas mestizas con predominio de Bos indicus en el municipio de Cauca, Colombia, se encuentran dentro de los rangos considerados como aceptables para el sistema de producción en sabana inundable.

\section{Agradecimiento}

Los autores agradecen al Comité Nacional de Investigaciones-CONADI de la Universidad Cooperativa de Colombia por el financiamiento de esta investigación, a los productores por facilitar la toma de la información y a los estudiantes integrantes del Semillero de Investigación de la Facultad de Medicina Veterinaria y Zootecnia por su dedicación al trabajo de campo

\section{Literatura Citada}

1. Arauca. 2016. Clima: Arauca, Colombia. Aeropuerto Santiago Pérez. [Internet]. Disponible en: http:// es.allmetsat.com/clima/venezuela. php? code $=80099$

2. Arellano $S$, Martínez J, Romero E, Briones F, Domínguez, M, De La Garza $F$. 2006. Factores genético-ambientales que afectan el intervalo entre partos y días a primer parto en ganado doble propósito en el Norte de Veracruz. Rev AIA 10(1): 43-53.

3. Azevêdo DM, Martins FR, Bozzi R, Forabosco F, Mendes CE. 2006. Parâmetros genéticos e fenotípicos do desempenho reprodutivo de fêmeas Chianina. R Brasil Zoot 35: 982-987. doi: 10.1590/S1516-35982006000400007

4. Chirinos Z, Faría-Mármol J. 2014. Incorporación de razas criollas venezolanas en un rebaño doble propósito II. Crecimiento y reproducción en novillas. AICA 4: 247-249.

5. Coronado LB, Arellano CM, Briones EF, Velasco CR. 2015. Intervalo entre partos en ganado suizo por cebú en el norte de Veracruz. [Internet]. Disponible en: http://www.engormix.com/MAganaderia-carne/articulos/ganaderia-tropical-intervalo-entre-t6819/p0.htm

6. Corrión A, Colmenares O, Herrera P, Birbe B, Martínez N. 2002. Factores que afectan el intervalo entre partos de un rebaño cebuino en condiciones de sa- 
banas bien drenadas. Rev Cient (Maracaibo) 12: 449-451.

7. De Alba J. 1985. Reproducción animal. México DF: Ed Prensa Médica Mexicana. 584 p.

8. Domínguez, C, Martínez N, Colmenares O. 2004. Características reproductivas de rebaños bovinos doble propósito en los Llanos Centrales de Venezuela. Zootec Trop 22: 133-145.

9. García G, Cárdenas C, Monterrosa MV, Valencia L, Maldonado J. 2002. Caracterización productiva $\mathrm{y}$ reproductiva de las explotaciones ganaderas del Bajo Cauca y el Litoral Atlántico antioqueños. I. Haciendas la Leyenda y la Candelaria. Rev Colomb Cienc Pec 15: 293-301.

10. González-Stagnaro C, RodríguezUrbina MA, Goicochea-Llaque J, Madrid-Bury N, González-Villalobos D. 2006. Crecimiento pre-destete en hembras bovinas doble propósito. Rev Cient (Maracaibo) 16: 288-296.

11. González-Stagnaro C, Madrid-Bury $N$, Goicochea-Laque J, GonzálezVillalobos D, Rodríguez-Urbina M. 2007. Primer servicio en novillas de doble propósito. Rev Cient (Maracaibo) 17: 39-46.

12. Hernández M, Silveira E, Molina R, Mendoza C, Vallejo G. 2010. Incorporación y primer parto en novillas Siboney en una empresa ganadera en Cuba. REDVET 11(12). [Internet]. Disponible en: http://www.veterinaria.org/revistas/ redvet/n121210/121013.pdf

13. Hernández-Reyes E, Segura-Correa VM, Segura-Correa J C, Osorio-Arce MM. 2000. Intervalo entre partos, duración de la lactancia y producción de leche en un hato de doble propósito en Yucatán, México. Agrociencia 34: 699705.

14. Holdridge LR. 1987. Ecología basada en zonas de vida. San José de Costa Rica: IICA. 216 p.

15. [IDEAM] Instituto de Hidrología, Meteorología y Estudios Ambientales. 2000. Clima: Climatografía de las prin- cipales ciudades. [Internet]. Disponible en: http://bart.ideam.gov.co/cliciu/arauca/ arauca.htm

16. Kaps M, Lamberson W. 2004. Biostatistics for animal science. London, UK: CABI Publishing. $459 \mathrm{p}$.

17. López J, Vaccaro L. 2002. Comportamiento productivo de cruces Holstein Friesian-cebú comparados con Pardo Suizo-cebú en sistemas de doble propósito en tres zonas de Venezuela. Zootec Trop 20: 397-414.

18. López R, Díaz M, García J, Núñez, López OR, Martínez P. 2010. Eventos reproductivos de vacas con diferente porcentaje de genes Bos taurus en el trópico mexicano. Rev Mex Cienc Pec 1: 325-336.

19. López-Montilla G. 2012. Características productivas de fincas doble propósito en el valle de Moroturo, municipio Urdaneta del Estado Lara. Rev Científ (Maracaibo) 22(Supl 1): 79 (Resumen).

20. Magaña J, Delgado R, Segura J. 2002. Factores ambientales y genéticos que influyen en el intervalo entre partos y el peso al nacer del ganado Cebú en el sureste de México. Rev Cubana Cienc Agríc 36: 317-322.

21. Medina GC, Pestana SJ. 2005. Factores que afectan el primer intervalo de parto de las hembras bovinas manejadas bajo el sistema doble propósito en la finca El Rodeo, municipio de Magangue, Bolívar. Tesis de Zootecnista. Sincelejo, Sucre: Universidad de Sucre, Colombia. $70 \mathrm{p}$.

22. Motta DP, Rivera CL, Mariño AA, Lizcano PC. 2012. Desempeño productivo y reproductivo de vacas F1 Gyr $\mathrm{x}$ Holstein en clima cálido colombiano. Vet Zoot 6: 17-23.

23. Osorio-Arce M, Segura-Correa J. 2010. Efectos raciales y ambientales sobre edad al primer parto e intervalo entre partos de vacas Brahman y sus cruces en el trópico húmedo de México. LRRD 22(8). [Internet]. Disponible en: http://www.1rrd.org/lrrd22/8/ osor22148.htm 
24. Ossa G, Suarez M, Pérez J. 2007. Factores ambientales y genéticos que influyen la edad al primer parto y el intervalo entre partos en hembras de la raza crio1la Romosinuano. Cienc Tecnol Agropec 8: 74-80.

25. Perotto D, Miyagi A, Souza J, Moletta J, Freitas J. 2006a. Estudos de características reprodutivas de animais da raça Canchim criados a pasto, no estado do Paraná Brasil. Arch Vet Sci 11(2): 1-6.

26. Perotto D, Abrahão JJ, Kroetz IA. 2006b. Intervalo de partos de fêmeas bovinas Nelore, Guzerá x Nelore, Red Angus x Nelore, Marchigiana x Nelore e Simental x Nelore. R Bras Zootec 35: 733-741. doi: 10.1590/S151635982006000300014

27. Pino T, Martínez GE, Galindez R, Castejón M, Tovar A. 2009. Efecto del grupo racial y algunos factores no genéticos sobre la producción de leche $\mathrm{e}$ intervalo entre partos en vacas de doble propósito. Rev Fac Cienc Vet 50: 224-228.

28. Rodríguez GY, Martínez GG. 2010. Efecto de la edad al primer parto, grupo racial y algunos factores ambientales sobre la producción de leche y el primer intervalo entre partos en vacas doble propósito. Rev Fac Cienc Vet 51: 79-91.

29. Salamanca CA. 2008. Productividad de un sistema de doble propósito en sabana inundable del municipio de Arauca. I Congreso Internacional Desarrollo y Producción Sostenible, versión sabanas inundables. Arauca, Colombia.

30. Sánchez G, Martínez G. 2010. Algunos factores no genéticos y de grupo racial que afectan la edad al primer parto en vacas doble propósito. Rev Fac Agron UCV 36: 125-133.

31. [SAS] Statistical Analysis System. 2006. User's guide for Windows environment 9.1.3. USA: SAS.
32. Sheen S, Riesco A. 2002. Factores que afectan la producción de leche en vacas de doble propósito en el trópico húmedo (Pucallpa). Rev Inv Vet Perú 13(1): 25-31.

33. Simón L, López O, Álvarez D. 2010. Evaluación de vacas de doble propósito de genotipos Holstein x Cebú en sistemas de pastoreo arborizado. I. Primíparas. Pastos y Forrajes 33(1): 1-9.

34. Suárez M, Ossa G, Pérez J. 2006. Factores ambientales y genéticos que influyen sobre la edad al primer parto en hembras de la raza Romosinuano. Rev MVZ Córdoba 11(1): 738-743.

35. Tadesse M, Dessie T. 2003. Milk production performance of Cebu, Holstein Friesian and their crosses in Ethiopia. LRRD 15(3). [Internet]. Disponible en: http://www.lrrd.org//rrd15/3/ Tade153.htm

36. Tuexi V, Martínez G 2001. Comportamiento reproductivo de un hato Gyr bajo condiciones de pastoreo en el centro de Tamaulipas. BIOTAM 12(2): 13-20.

37. Vergara G, Botero A, Martínez B. 2009. Factores que afectan la edad al primer parto y primer intervalo de partos en vacas del sistema doble propósito. Rev MVZ Córdoba 14: 1594-1601.

38. Vergara G, Salgado O, Maza A, Botero A, Martínez B, Medina G, Pestana S. 2007. Factores que afectan el primer intervalo de parto de hembras bovinas manejadas bajo el sistema doble propósito. LRRD 19(10). [Internet]. Disponible en: http://www.1rrd.org/lrrd19/10/ verg19140.htm

39. Zambrano S, Contreras G, Pirela M, Cañas H, Olson T, LandaetaHernández A. 2006. Milk yield and reproductive performance of crossbred Holstein x Criollo Limonero cows. Rev Científ(Maracaibo) 16: 155-164. 